\title{
Application of MODIS snow cover products: wildfire impacts on snow and melt in the Sierra Nevada
}

\author{
P. D. Micheletty ${ }^{1}$, A. M. Kinoshita ${ }^{2, *}$, and T. S. Hogue ${ }^{1,2}$ \\ ${ }^{1}$ Hydrologic Sciences and Engineering, Colorado School of Mines, Golden, CO 80401, USA \\ ${ }^{2}$ Department of Civil and Environmental Engineering, Colorado School of Mines, Golden, CO 80401, USA \\ *now at: Department of Civil, Construction, and Environmental Engineering, San Diego State University, \\ San Diego, CA, USA
}

Correspondence to: T. S. Hogue (thogue@ mines.edu)

Received: 14 May 2014 - Published in Hydrol. Earth Syst. Sci. Discuss.: 4 July 2014

Revised: - - Accepted: 13 October 2014 - Published: 24 November 2014

\begin{abstract}
The current work evaluates the spatial and temporal variability in snow after a large forest fire in northern California using Moderate Resolution Imaging Spectroradiometer (MODIS) snow-covered area and grain size (MODSCAG). MODIS MOD10A1 fractional snow-covered area and MODSCAG fractional snow cover products are utilized to detect spatial and temporal changes in snowpack after the 2007 Moonlight Fire and an unburned basin, Grizzly Ridge, for water years (WY) 2002-2012. Estimates of canopy-adjusted and non-adjusted MODSCAG fractional snow-covered area (fSCA) are smoothed and interpolated to provide a continuous time series of average daily snow extent over the two basins. The removal of overstory canopy by wildfire exposes more snow cover; however, elemental pixel comparisons and statistical analysis show that the MOD10A1 product has a tendency to overestimate snow coverage pre-fire, muting the observed effects of wildfire. The MODSCAG algorithm better distinguishes subpixel snow coverage in forested areas and is highly correlated to soil burn severity after the fire. Annual MODSCAG fSCA estimates show statistically significant increased fSCA in the Moonlight Fire study area after the fire $(P<0.01$ for WY 2008-2011) compared to pre-fire averages and the control basin. After the fire, the number of days exceeding a pre-fire high snow-cover threshold increased by $81 \%$. Canopy reduction increases exposed viewable snow area and the amount of solar radiation that reaches the snowpack, leading to earlier basin average melt-out dates compared to the nearby unburned basin. There is also a significant increase in MODSCAG fSCA post-fire regardless of slope or burn severity.
\end{abstract}

Regional snow cover change has significant implications for both short- and long-term water supply for impacted ecosystems, downstream communities, and resource managers.

\section{Introduction}

The last several decades have been marked by distinct increases in large-wildfire frequency as well as fire duration and season across the western US (Westerling et al., 2006). Soil and vegetation change after fires result in increased flooding, mass wasting, increased runoff intensities, long-term changes in energy and water budgets, and increased air pollutants (Swanson, 1981; Kattelmann et al., 1983; Stednick, 1996; Webb et al., 2012). Storm runoff also liberates atmospherically deposited contaminants and mobilizes particulate-bound constituents, degrading post-fire water quality (Stein et al., 2012; Burke et al., 2013). Vegetation recovery significantly controls long-term hydrologic conditions; additionally, elevated discharge has been observed for nearly 10 years post-fire (Kinoshita and Hogue, 2011). Similarly, forest canopy considerably influences snowpack properties and snowmelt response (Faria et al., 2000). Given the dependency of the western US on snowpack and mountain runoff for water supply and the assumption of stationarity, under which water reservoir systems are designed and managed (Milly et al., 2008), minimal forest structure alterations will have critical implications for regional and state water resources and management. 
Field-based studies have found that disturbance of forest structure considerably impacts snow accumulation and melt properties, altering water yield from snow-dominated basins (Kattelmann et al., 1983; Stednick, 1996; Faria et al., 2000; Stephens et al., 2012; Webb et al., 2012). Post-fire changes in snowpack energy balance include increased exposure to radiation, decreased snow albedo due to surface alterations from charred soils, dust, or vegetation, and changes in soil temperature (Painter et al., 2007; Burles and Boon, 2011; Ebel et al., 2012; Gleason et al., 2013; Harpold et al., 2013). The opposing effects of increased snow accumulation and increased snow ablation have been documented at the plot scale for the first year following a wildfire (Gleason et al., 2013; Harpold et al., 2013). Plot-scale studies generally reported significant increases in snow accumulation in burned areas compared to nearby control plots due to the lack of canopy interception (Burles and Boon, 2011; Harpold et al., 2013). Decreased canopy cover reduces snow interception, increases solar radiation exposure, and alters sublimation of the exposed snowpack (Faria et al., 2000; Varhola et al., 2010; Harpold et al., 2013). Harpold et al. (2013) showed winter season ablation reduced snowpack depths by $50 \%$ prior to melting and a $10 \%$ reduction in snow water equivalent in burned areas the first year after a fire. Gleason et al. (2013) showed a $40 \%$ decrease in snow albedo accompanied by a $200 \%$ increase in net shortwave radiation in burned forest plots compared to unburned forests. However, effects are undocumented at the watershed scale and there is a paucity of studies on snow accumulation and melt variability from forest cover change (Varhola et al., 2010).

Remote sensing products, including NASA Moderate Resolution Imaging Spectroradiometer (MODIS) MOD10A1 and MODIS snow-covered area and grain size (MODSCAG), a spectral mixing product, provide the spatial and temporal resolution necessary for monitoring large-scale wildfires that often impact inaccessible and ungaged snow-dominated basins. To our knowledge, no study has investigated pre-fire and post-fire snow cover change using satellite imagery. The current study facilitates identification of remote sensing tools capable of detecting spatial and temporal changes in post-fire snowpack through application of MODIS MOD10A1 and MODSCAG fractional snow-covered area (fSCA) products to the 2007 Moonlight Fire in the northern Sierra Nevada, California. Specifically, the objectives of our work are to (1) understand spatial and temporal variability of pre- and post-fire fSCA with MODIS (MOD10A1 and MODSCAG) products; (2) compare MOD10A1 and MODSCAG products in pre- and post-fire conditions to determine which product is more suitable for identifying change in snow-covered area (SCA) after fire; (3) investigate the influence of aspect, burn severity, and general climate patterns on post-fire snow behavior (using fSCA as a proxy); (4) evaluate post-fire recovery patterns in a snow-dominated basin over several years.

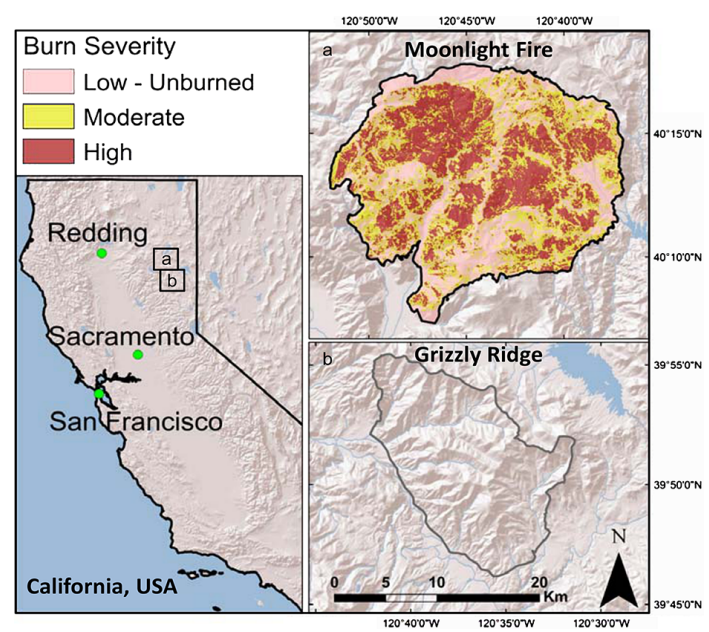

Figure 1. Map of the Moonlight Fire burned area with soil burn severity and control basin Grizzly Ridge.

\section{Study areas}

\subsection{Moonlight Fire}

There is a statistically significant $(P<0.05)$ increase in total annual area burned in the Sierra Nevada from the 1980s to the present. The decadal average of annual burned area increased from 300 in the 1980 s to a current $900 \mathrm{~km}^{2}$ in the 2010s (Wildland Fire Incidents, 2013). The Moonlight Fire burned over $250 \mathrm{~km}^{2}$ (27 $370 \mathrm{ha}$ ) in the Plumas National Forest (about $190 \mathrm{~km}$ north of Sacramento) from 3 to 15 September 2007 on the eastern side of the northern Sierra Nevada divide (Fig. 1). Since the late 1800s this was the first major wildfire recorded in this area (California Department of Forestry and Fire Protection, 2012). Steep terrain and high winds caused a mosaic of soil burn severities resulting in concentrated areas of highly burned areas surrounded by moderately to low unburned areas (USDA Forest Service RSAC, 2007; Fig. 1). Pre-fire vegetation consisted of mostly evergreen forest $(90 \%)$ with some riparian and shrub/scrub areas (Fry et al., 2011; Table 1). The slope aspects within the Moonlight Fire are relatively evenly distributed (Table 1). The Moonlight Fire burn area has an elevation range of 1090 to $2290 \mathrm{~m}$ and receives an average of $680 \mathrm{~mm}$ of precipitation a year, the majority of which falls in the winter months as snow (Table 1).

\subsection{Grizzly Ridge}

To evaluate the fire signal relative to regional climate variability, a complimentary regional control basin, Grizzly Ridge, was chosen for comparison. The Grizzly Ridge area has not burned within the last 100 years of record (California Department of Forestry and Fire Protection, 2012). Its area is $150 \mathrm{~km}^{2}$ (14800 ha), located approximately $24 \mathrm{~km}$ south of the area of the Moonlight Fire on the same side of the 
Table 1. Domain attributes for the Moonlight Fire and Grizzly Ridge.

\begin{tabular}{lcc}
\hline Domain attributes & 2007 Moonlight Fire & Grizzly Ridge \\
\hline Area [ha] & 27370 & 14800 \\
Elevation range [m] & $1090-2290$ & $1300-2320$ \\
Average annual & & \\
Precipitation [mm] & 680 & 880 \\
\hline \multicolumn{2}{c}{ NLCD Land cover } \\
Evergreen forest & $89 \%$ & $78 \%$ \\
Shrub/scrub & $9 \%$ & $21 \%$ \\
Misc. & $2 \%$ & $1 \%$ \\
\hline & \multicolumn{2}{c}{ Soil-burn severity } \\
High & $37 \%$ & N/A \\
Moderate & $18 \%$ & N/A \\
Low-unburned & $45 \%$ & $17 \%$ \\
\hline & \multicolumn{2}{c}{ Slope aspect } \\
North & $21 \%$ & $42 \%$ \\
South & $33 \%$ & $16 \%$ \\
East & $20 \%$ & $25 \%$ \\
West & $26 \%$ & \\
\hline
\end{tabular}

Sierra Nevada divide (Fig. 1). Vegetation within the Grizzly Ridge area is comprised of mostly evergreen forest $(80 \%)$ and shrub/scrub in the lower elevations (Fry et al., 2011; Table 1). The slope aspects exhibits similar patterns as Moonlight Fire, although Grizzly Ridge has roughly $10 \%$ more south-facing slopes (Table 1). The Grizzly Ridge area has an elevation range of $1300-2320 \mathrm{~m}$ and receives an annual basin average of $880 \mathrm{~mm}$ of precipitation.

\section{Methods}

MODIS MOD10A1 and MODSCAG products were gathered for both the area of the Moonlight Fire and Grizzly Ridge from 1 October 2001 to 30 September 2012 (water year (WY) 2002-2012). Both products only identify areas covered by snow, not snowpack depth - a longer snow season will distinguish more fSCA, but not depth changes or snow water equivalent. Annual and monthly precipitation and maximum and minimum temperatures for the Moonlight Fire area and Grizzly Ridge were estimated from the Parameter-elevation Regressions on Independent Slopes Model (PRISM) climate data set (Daly, 1994, 1997, 2002). Conterminous US products are downloaded from the PRISM Climate Group (http://www.prism.oregonstate.edu/) and the monthly $4 \mathrm{~km}$ pixels are extracted within the Moonlight Fire area and Grizzly Ridge and averaged over both domains for WY 2002-2012.

\subsection{Remote sensing products}

\subsubsection{MODIS MOD10A1}

The Terra MODIS SCA product (MOD10A1) provides atmospherically corrected daily fractional snow cover at $500 \mathrm{~m}$ spatial resolution based on the normalized difference snow index (NDSI). The preprocessed MODIS product includes spectral thresholds that mask and screen for clouds and lowreflectance surfaces such as water (Salomonson and Appel, 2004). To account for snow in densely vegetated areas, Klein et al. (1998) developed a method that uses a combined snow reflectance model and canopy reflectance model to map more snow in forested areas using normalized NDSI and the normalized difference vegetation index (NDVI; Klein et al., 1998). The NDVI normalizes reflectance in the nearinfrared and visible (red) wavelengths to differentiate vegetation where there is chlorophyll absorption of red light for photosynthesis and reflection of near-infrared light (Tucker, 1979):

$\mathrm{NDVI}=\frac{R_{\mathrm{NIR}}-R_{\mathrm{VIS}}}{R_{\mathrm{NIR}}+R_{\mathrm{VIS}}}$,

where $R_{N I R}$ is near-infrared reflectance and $R_{V I S}$ is red reflectance in the visible spectrum. The NDSI is evaluated as (Dozier, 1989)

$\mathrm{NDSI}=\frac{R_{\mathrm{VIS}}-R_{\mathrm{SWIR}}}{R_{\mathrm{VIS}}+R_{\mathrm{SWIR}}}$,

where $R$ represents spectral reflectances in the visible and shortwave infrared bands. The vegetation correction is used to map snow when NDSI $<0.4$ and NDVI $>0.1$.

Version 5 of MOD10A1 contains a daily, $500 \mathrm{~m}$ fractional snow-covered area product available from 2000 to the present (Hall et al., 2006). MOD10A1 fSCA is based on an empirical snow-mapping algorithm developed from a linear regression between binary Landsat Thematic Mapper snow cover and MODIS NDSI (Salomonson and Appel, 2004; Hall et al., 2006):

$\mathrm{fSCA}=-0.01+1.45 \mathrm{NDSI}$.

This algorithm is used to map fractional snow cover and performs relatively well in the winter months in mountainous regions compared to other remote sensing products and ground-based observations (Maurer et al., 2003; Pu et al., 2007).

\subsubsection{MODSCAG}

MODSCAG is derived from a physically based algorithm which uses a multispectral mixing analysis to identify subpixel snow-covered area and grain size (Painter et al., 2009). The MODSCAG model has been validated over the Sierra Nevada, Rocky Mountains, high plains of Colorado, and Himalayas using Landsat fSCA, field data, and in situ albedo 
observations (Painter et al., 2009). The MODSCAG algorithm solves a combination of linear equations to identify the best mixture of endmember components that make up the surface reflectance of a pixel from the MODIS atmospherically corrected surface spectral-reflectance product, MOD09GA (Painter et al., 2009):

$R_{S, \lambda}=\sum_{k} F_{k} R_{\lambda, k}+\varepsilon_{\lambda}$,

where $R_{S, \lambda}$ is the average surface reflectance from MODIS in wavelength $\lambda, F_{k}$ is the fraction of endmember $k$ (snow, vegetation, soil, rock, etc.), $R_{\lambda, k}$ is the surface reflectance of endmember $k$ in wavelength band $\lambda$, and $\varepsilon_{\lambda}$ is the residual error at $\lambda$ for all endmembers. Non-snow endmembers are gathered from a library of hyperspectral field and laboratory observations. MODSCAG uses a library of spectral reflectances generated from the hemispherical-directional reflectance factor with a discrete-ordinates radiative transfer model to identify snow endmembers (Painter et al., 2009). This method utilizes the shape of the snow's spectrum rather than absolute reflectance. A simultaneous solution of subpixel snow surface grain size and fractional snow cover is necessary, assuming that spectral reflectance of snow endmembers are sensitive to surface grain size.

MODSCAG analyzes the linear mixtures of endmember spectral libraries and selects the optimal model with the smallest error relative to MOD09GA surface reflectance and the fewest number of endmembers. If snow endmembers are identified, MODSCAG will attribute a snow-covered area and grain size based on the fraction of the snow endmember in the pixel. The MODSCAG snow-mapping algorithm for fSCA results in an average root-mean-square error (RMSE) of $\sim 5 \%$ (Rittger et al., 2013). MODSCAG shows less sensitivity to regional canopy cover and is noted to more accurately identify snow cover throughout the year compared to MOD10A1 (Rittger et al., 2013). The current study incorporates MODSCAG to evaluate pre- and post-fire snow-covered area relative to the MOD10A1 product for the Moonlight Fire area and Grizzly Ridge.

\subsubsection{Canopy adjustment}

Forest canopy obstructs the view of the ground by MODIS, causing underestimates of snow cover in dense forests (Raleigh et al., 2013). Hence, forest cover density data are used to indicate snow cover masked by canopy and improve MODSCAG estimates of viewable snow cover (Molotch and Margulis, 2008):

$\mathrm{fSCA}_{\mathrm{Adj}}=\frac{\mathrm{fSCA}_{\mathrm{Ob}}}{1-\mathrm{fVeg}}$,

where $\mathrm{fSCA}_{\mathrm{ob}}$ is the observed MODSCAG fSCA and fVeg is the annual density of forest cover or the fraction of vegetation. For 2000 to $2010 \mathrm{fVeg}$ is estimated from the MODIS (MOD44B) percent tree cover product (DiMiceli et al., 2011). The percent tree cover product from MOD44B is derived from annual composites of MODIS data using an automated supervised regression tree algorithm and is available for the years 2000-2010. The MOD44B product is updated annually and has been used extensively to investigate land cover change and forest disturbance (Hansen et al., 2003; Morton et al., 2005). For the years 2011 and 2012 the MODSCAG fraction of vegetation product is used to estimate fVeg. For consistency, 2011 and 2012 MODSCAG fraction of vegetation is adjusted based on a linear regression of annual composites of MODSCAG fraction of vegetation and MOD44B percent tree cover. The canopyadjusted fSCA (Eq. 5) assumes that the distribution of snow under a canopy is equivalent to viewable open areas between trees or in clearings. This assumption that spatial distribution of snow in viewable gaps can be interpolated to nearby canopied forests is not as reliable during the accumulation and melt periods (Raleigh et al., 2013). A rigorous correction to improve estimations of snow under a canopy using optical sensors remains an area of active research for remote sensing in forested terrains and is outside the scope of this study. In the current study, MODSCAG fSCA is adjusted for canopy cover (Eq. 5), whereas the MOD10A1 SCA is distributed with vegetation-corrected fSCA (Klein et al., 1998) and does not require further modification.

\subsection{Spatial and temporal analysis}

\subsubsection{Basin fSCA interpolation}

Temporal analysis for WY 2002-2012 uses daily basinaveraged MODSCAG fSCA for both the Moonlight Fire area and Grizzly Ridge. The daily data initially have gaps and errors from cloud cover, sensor viewing geometry, or imperfections in the retrieval algorithm. A combination of noise filtering, snow/cloud discrimination, interpolation, and smoothing improves the MODSCAG daily snow cover time series (Dozier et al., 2008). Dozier et al. (2008) view the snow data as a space-time cube that can be filtered, smoothed, and interpolated. In the current study, the space-time cube is filtered to remove cloudy or noisy values; the remaining data are used to interpolate and smooth gaps within the cube.

Filtering consists of several steps: (1) a two-dimensional adaptive Wiener filter (Matlab wiener2 function) is used to identify noise and data dropouts in all seven land reflectance bands, where the Boolean variable is set to 1 for raw fractional snow-covered area that is 0 ; (2) quality flags from the MOD09 product are used to identify snow-covered pixels as cloudy. False positives and false negatives are identified from MODSCAG snow cover (fSCA) and grain size $(r)$ processing, and then thresholds (false positives: fSCA $>0.6 \wedge r \geq$ $100 \mu \mathrm{m}$ and false negatives: fSCA $>0.6 \wedge r \leq 100 \mu \mathrm{m})$ are used to reduce misidentification; (3) to correct for values obscured by MODIS scan angles (the primary source of error), the time dimension of the space-time cube is interpolated 
using a cubic smoothing spline (Matlab csaps function). The current study uses 16 days (representing a MODIS viewing angle cycle) for the limits of integration; the smoothing parameter is adaptive and varies spatially depending on the extent of cloud cover or missing data. The weight varies from 0 to 1 and is based on the viewing angle (determined from the corresponding MOD09GA) such that the near-nadir views have the greatest weights. If the cubic smoothing spline yields unrealistic values from gaps in data, the smoothed fSCA values are interpolated using a piecewise interpolant; (4) after steps 1-3 the whole cube is smoothed with a Gaussian filter, providing a continuous data stream of the snowcovered area.

\subsubsection{Elemental pixel comparison}

Difference maps for each gridded fSCA product, MOD10A1 and MODSCAG, are developed by taking the difference between winter (January-March) pre-fire average fSCA (WY 2002-2007) and post-fire average fSCA (WY 2008-2012); the domain includes 1099 pixels. The difference maps ( $\triangle \mathrm{fSCA})$ are used to detect spatial changes in viewable snow cover after the fire. An elemental pixel comparison (EPC) between MODSCAG fSCA and MOD10A1 fSCA is evaluated using a least-squares linear regression analysis of individual pre- and post-fire winter pixels. EPC is also used to investigate temporal changes in snow cover based on corresponding basin attributes including burn severity and slope aspect. Gridded daily fSCA is disaggregated over each domain by slope aspects (north, south, east, and west) derived from a USGS National Elevation Dataset $30 \mathrm{~m}$ digital elevation model. Daily basin average estimates are then produced for each slope aspect for WY 2002 to 2012 for Grizzly Ridge and the Moonlight Fire region. For the Moonlight Fire region, daily fSCA was also disaggregated to match a $30 \mathrm{~m}$ soil burn severity map (based on Landsat burned area reflectance from the USDA Forest Service RSAC, 2007) for EPC. A time series of basin-averaged fSCA is made based on each burn severity (i.e., high, moderate, and low unburned) from WY 2002 to 2012 for statistical analysis.

\subsection{Statistical analysis}

\subsubsection{MODSCAG cumulative distribution function}

Annual cumulative distribution functions (CDFs) are developed using daily basin-averaged fSCA for both the area of the Moonlight Fire and Grizzly Ridge to investigate annual shifts in snow cover after fire. Fractional SCA cumulative distribution functions are similar to flow duration curves, which are used to investigate annual changes in flow regimes due to forest disturbance (Lane et al., 2006; Brown et al., 2005). Fractional SCA CDFs are used to determine the probability of a specific basin-averaged fSCA being equaled or exceeded during a given time period. Exceedance probabil- ities are derived from the pre-fire MODSCAG fSCA CDF curves and are used to establish high and low thresholds for analysis. High snow-cover days are defined based on the prefire long-term CDFs with an exceedance probability of $10 \%$ or less.

During the beginning and end of the snow season, as MODSCAG and MOD10A1 pixels approach an fSCA value of $15 \%$ (very low fractional snow-covered area), there is increased uncertainty and larger errors in positively identifying snow (Rittger et al., 2013). This study uses an exceedance probability of $70 \%$ (representing $10 \%$ basin-averaged snow cover) to identify an unbiased low SCA melt-out threshold and reduce error from misidentification of snow. This $70 \%$ exceedance probability threshold commonly represents lower quartiles in CDFs and also corresponds to the most widely used definition of low flow as derived from flowduration curves (70-99\%; Smakhtin, 2001).

To quantify the change from pre-fire to post-fire a twosample Kolmogorov-Smirnov (KS) test is used to compare the distributions of pre- and post-fire fSCA CDFs. The KS null hypothesis is that the pre- and post-fire fSCA CDFs are from the same continuous distribution at $\alpha=0.01$ (Massey, 1951), where the KS test statistic is the maximum vertical distance between the two curves being evaluated (Cowpertwait et al., 2013).

\subsubsection{Analysis of variance}

Analysis of variance (ANOVA) is used to determine the statistical significance of temporal changes in snow cover after the fire. Daily basin-averaged fSCA estimates are separated annually based on the water year, excluding summer months (July-September), and by basin attributes (burn severity and slope aspect). The fSCA is then evaluated for statistical differences from the pre-fire period and compared to the control domain (Grizzly Ridge). The null hypothesis that the mean of each post-fire annual fSCA (WY 2008-2012) is similar to the pre-fire annual mean (WY 2002-2007) is tested at $\alpha=0.01$.

\section{Results}

\subsection{MODSCAG and MOD10A1 comparison}

Non-canopy-adjusted MODSCAG and MOD10A1 difference maps for the Moonlight Fire area show a distinct difference in FSCA after the fire (Fig. 2). Generally the spatial pattern of the increased fSCA for both products follows the high soil burn severity in the Moonlight Fire. Higher soil burn severity near the center of the domain results in reduced canopy cover and more visible snow and snow-covered area. An EPC and linear regression of $\triangle \mathrm{fSCA}$ and soil burn severity shows a stronger correlation of non-canopyadjusted MODSCAG $\triangle \mathrm{fSCA}$ to soil burn severity $(r=0.56)$ than MOD10A1 $\triangle$ fSCA $(r=0.43)$. Non-canopy-adjusted 

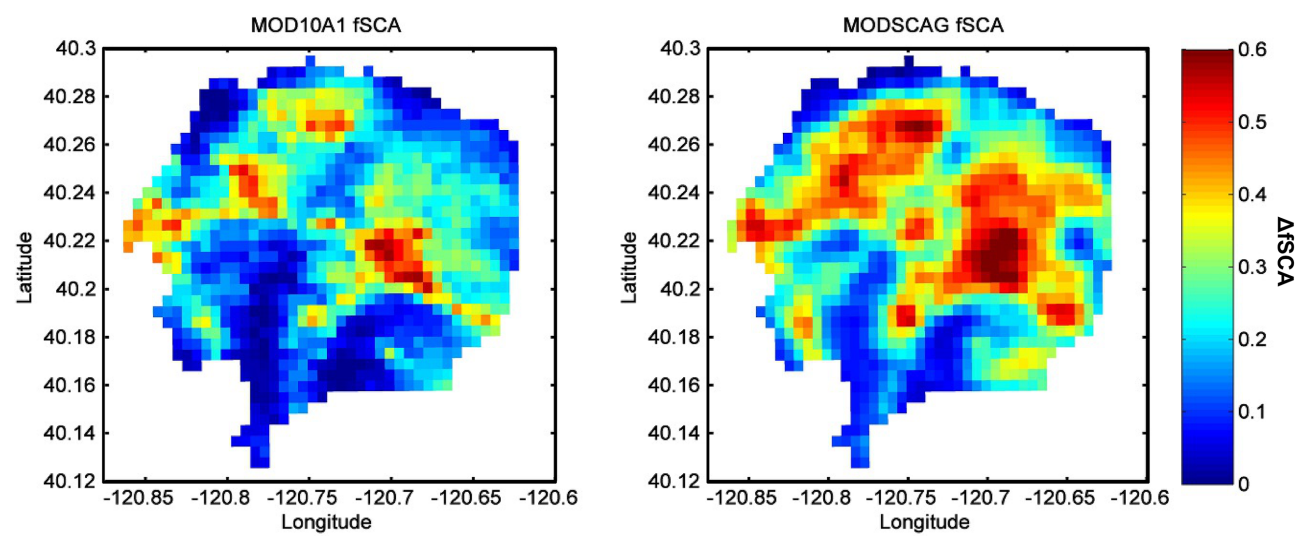

Figure 2. Pre- and post-fire MOD10A1 fSCA (left) and non-canopy-adjusted MODSCAG fSCA (right) difference maps for winter (JanuaryMarch) over the region of the Moonlight Fire. Each image contains 1099 pixels.

MODSCAG has a basin average increase in ISCA of 0.3 (Fig. 2, right) after the fire, whereas MOD10A1 displays smaller differences throughout the burned domain and increases on average by 0.2 (Fig. 2, left). For the MODSCAG product, $44 \%$ of the Moonlight Fire domain exhibited $\triangle \mathrm{fSCA}$ values of least 0.3 , while MOD10A1 has $21 \%$ of the domain with values of 0.3 or higher.

The least-squared linear regression analysis of MOD10A1 fSCA and MODSCAG fSCA established from the EPC shows a distinct difference between pre- and post-fire correlation (Fig. 3). MOD10A1 tends to produce higher estimates of fSCA compared to MODSCAG across the entire domain pre- and post-fire. MOD10A1 is biased high compared to MODSCAG, but the pre-fire linear correlation between the two products is relatively high $(r=0.85)$. After the fire there is an increase in variability and the linear relationship between MOD10A1 and MODSCAG decreases $(r=0.69)$. The linear regression line is also higher post-fire (Fig. 3). The upward shift in the regression line in the MODSCAG direction is consistent with the increase in visible fSCA (Fig. 2). Decreases in the correlation coefficient after the fire are most likely due to differences in the amount of increased fSCA identified by each product.

Product assessment studies have shown that MOD10A1 fSCA overestimates snow cover in densely vegetated areas (Rittger et al., 2013). These results are consistent with our linear regression analysis. This can be attributed to the MOD10A1 snow-mapping algorithm and NDVI threshold indices (Klein et al., 1998) that are used to identify snow in forested areas. NDVI is a greenness index based on surface reflectance and does not differentiate vegetation types. Therefore, the current NDVI threshold $(>0.1)$ increases mapped snow cover in areas with shrubs and grasses just as it does for forested areas. Reduced canopy cover from wildfire should lead to increased viewable snow cover from satellite observations. Due to overestimates in SCA before the fire, this signal is muted in MOD10A1. The EPC re-

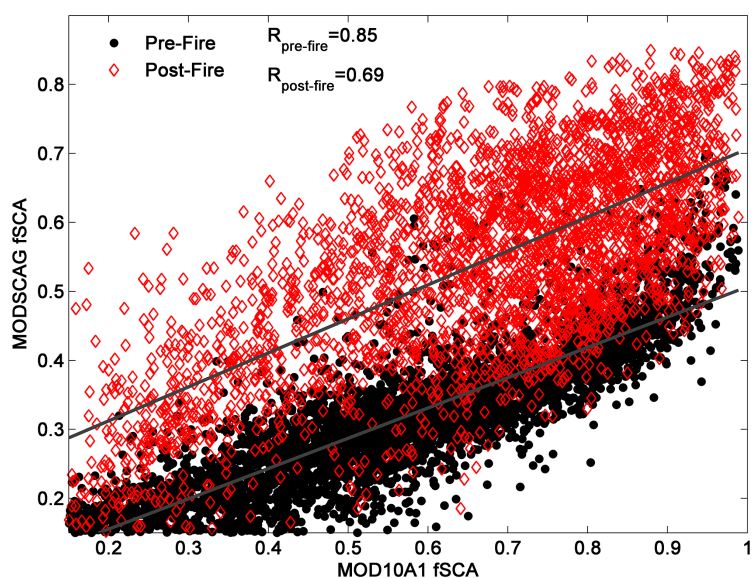

Figure 3. Least-squared linear regression analysis of MOD10A1 and non-adjusted MODSCAG over the Moonlight Fire domain pre(black circles) and post-fire (red diamonds).

sults prompted the utilization of MODSCAG FSCA for the remainder of the current study because of the overestimation biases associated with the MOD10A1 fSCA product as well as its lower spatial correlation to soil burn severity. The combination of these results and MODSCAG's more rigorous snow-mapping algorithm, which also takes into account snow grain size, provides us with higher confidence in the pre- and post-fire fSCA estimates that will be used for further analysis.

\subsection{MODSCAG time series analysis}

Daily basin-averaged canopy-adjusted and non-canopyadjusted MODSCAG fSCA, monthly precipitation, and temperature (maximum and minimum) are plotted for the Moonlight Fire domain and Grizzly Ridge for the entire study period (Fig. 4). Pre-fire average annual precipitation for the Moonlight Fire domain is $730 \mathrm{~mm}$ and for Grizzly Ridge 


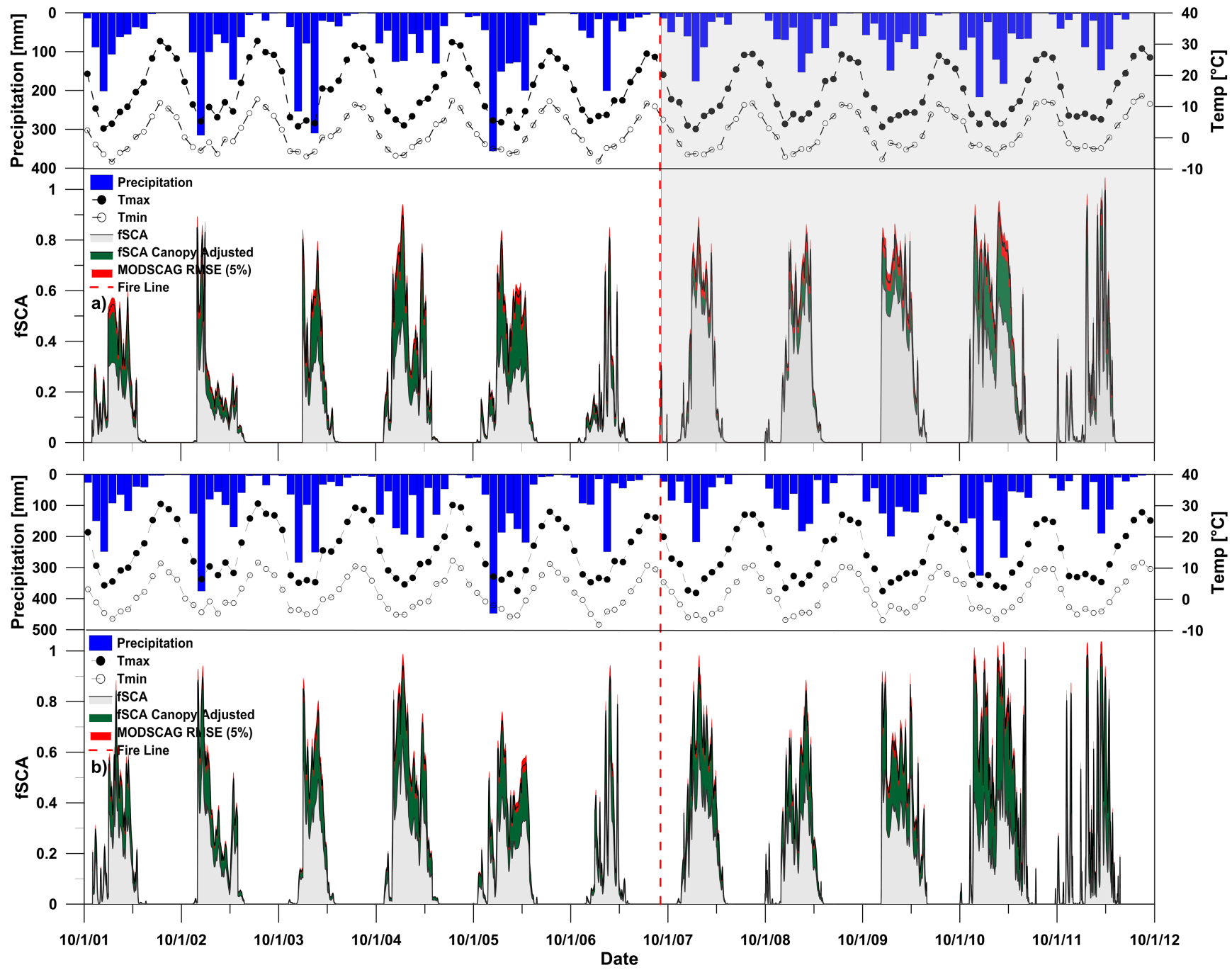

Figure 4. Time series of PRISM monthly precipitation totals, minimum and maximum temperatures, and daily basin-averaged MODSCAG fSCA for the Moonlight Fire domain (a) and Grizzly Ridge (b) for WY 2002 to 2012.

is $900 \mathrm{~mm}$. Post-fire annual precipitation totals are less for both the Moonlight Fire region and Grizzly Ridge (560 and $800 \mathrm{~mm}$, respectively). Temperature trends for each domain are very similar, with the region of the Moonlight Fire and Grizzly Ridge averaging around $9^{\circ} \mathrm{C}$ before the fire and $8{ }^{\circ} \mathrm{C}$ after. Over the 10-year time series the fSCA ensembles are more sensitive to the duration of the winter precipitation season (season in which precipitation occurred at temperatures below $0^{\circ} \mathrm{C}$ ) than the total snowfall. The largest fSCA year before the fire (WY 2005) was not during the period of the highest total winter precipitation (710 and $990 \mathrm{~mm}$ for the region of the Moonlight Fire and Grizzly Ridge, respectively); however, it did exhibit the longest snow season (Fig. 4; Table 2).

Daily averaged MODSCAG fSCA estimates are uniformly increased based on the annual fraction of vegetation within the canopy adjustment algorithm (Eq. 5; Fig. 4). The pre-fire average fSCA for the area of the Moonlight Fire and Grizzly Ridge is 0.13 and 0.15 , respectively, while the post-fire average fSCA is 0.23 for the Moonlight Fire area and 0.18 for Grizzly Ridge. Prior to the fire, both fSCA ensembles follow very similar trends $(r=0.96)$. After the fire, the nonadjusted fSCA values in the area of the Moonlight Fire increase and approach the canopy-adjusted fSCA curve due to significant reductions in canopy cover. Pre-fire, the average difference in canopy-adjusted and non-adjusted fSCA ensembles is approximately 0.30 for both Grizzly Ridge and the area of the Moonlight Fire, while after the fire the difference decreased in the Moonlight Fire area on average to 0.18 . The non-adjusted MODSCAG fSCA values show a significant increase in basin-averaged fSCA (or exposed snow cover) after the Moonlight Fire in $2007(P<0.01)$ due to the standreplacing fire (Fig. 4). MODSCAG fSCA increased, but the canopy adjustment has no statistically significant increase in 
Table 2. Length of snow season compared to total winter precipitation for the area of the Moonlight Fire and Grizzly Ridge. Post-fire years are set in bold.

\begin{tabular}{lcc}
\hline Moonlight & $\begin{array}{c}\text { Length of snow } \\
\text { season [days] }\end{array}$ & $\begin{array}{c}\text { Total winter } \\
\text { precipitation }[\mathrm{mm}]\end{array}$ \\
\hline WY 2002 & 100 & 610 \\
WY 2003 & 120 & 890 \\
WY 2004 & 90 & 760 \\
WY 2005 & 160 & 710 \\
WY 2006 & 140 & 1000 \\
WY 2007 & 60 & 410 \\
WY 2008 & $\mathbf{1 2 0}$ & $\mathbf{4 5 0}$ \\
WY 2009 & $\mathbf{1 3 0}$ & $\mathbf{5 6 0}$ \\
WY 2010 & $\mathbf{1 4 0}$ & $\mathbf{5 9 0}$ \\
WY 2011 & $\mathbf{1 7 0}$ & $\mathbf{8 2 0}$ \\
WY 2012 & $\mathbf{1 0 0}$ & $\mathbf{3 8 0}$ \\
\hline Grizzly & Length of snow & Total winter \\
Ridge & season [days] & precipitation $[\mathrm{mm}]$ \\
\hline WY 2002 & 90 & 780 \\
WY 2003 & 120 & 970 \\
WY 2004 & 110 & 800 \\
WY 2005 & 150 & 990 \\
WY 2006 & 130 & 1300 \\
WY 2007 & 60 & 560 \\
WY 2008 & 140 & 610 \\
WY 2009 & 140 & 790 \\
WY 2010 & 160 & 870 \\
WY 2011 & 180 & 1200 \\
WY 2012 & 60 & 520 \\
\hline
\end{tabular}

annual fSCA. However, exposed areas with increased viewable fSCA exhibit altered accumulation and melt behavior due to changes in the snowpack energy budget and are further analyzed with both canopy-adjusted and non-adjusted fSCA.

\subsection{MODSCAG cumulative distribution functions}

Annual CDFs of basin-averaged non-canopy-adjusted and canopy-adjusted MODSCAG fSCA for both the Moonlight Fire area and Grizzly Ridge highlight shifts in viewable snow cover after the fire (Fig. 5). The spread in the prefire (Fig. 5; black) cumulative distribution functions are attributed to snow season climate variability. For post-fire water years 2008-2011 the annual cumulative distribution functions are statistically different from the pre-fire curve $(P<$ 0.01), and the null hypothesis is rejected. However, WY 2012 falls within the pre-fire distributions and is not statistically different. The KS statistic indicates post-fire non-adjusted fSCA distributions are elevated on average by $40 \%$ compared to pre-fire non-adjusted curves. The canopy-adjusted fSCA curves are not as sensitive, but still increase by $14 \%$ after the fire. The distribution of the post-fire curves in the
Moonlight Fire area is generally higher compared to Grizzly Ridge and is especially apparent using the non-adjusted fSCA (Fig. 5a). The shape of the fSCA curves significantly change after the fire due to the upward shift in inflection points. This shifting distribution indicates a higher post-fire probability that the basin will have larger areas of exposed snow coverage.

Using the thresholds established from the cumulative distribution functions, the consecutive number of high snowcover days with respect to the length of snow season are shown for the Moonlight Fire area (Fig. 6a and b) and Grizzly Ridge (Fig. 6c and d). Post-fire, there are more days with high snow cover in the Moonlight Fire region than pre-fire and compared to Grizzly Ridge for both canopy-adjusted (Fig. 6c and d) and non-canopy-adjusted fSCA values (Fig. 6a and b). On average, there are 13 days that exceed the high snowcover threshold in the region before the fire, whereas there are on average 70 days classified as high snow cover after the fire. Temporal distributions highlight daily basin-averaged SCA patterns throughout each year for both canopy-adjusted and non-adjusted (Fig. 6, right). Larger fSCA patterns are noticeable during winter months (12 December through 5 April) after the fire. The canopy-adjusted fSCA plots (Fig. 6b and d) have larger values relative to the non-canopy-adjusted due to the linear scaling based on the vegetation fraction (Fig. 6a and c); and is congruent with the annual cumulative distribution functions (Fig. 5).

\subsection{ANOVA}

An ANOVA of non-adjusted MODSCAG fSCA shows that post-fire annual basin-averaged fSCA for WY 2008-2011 are significantly higher than pre-fire averages in the Moonlight Fire basin at $\alpha=0.01(P<0.01$; Fig. 7). For the prefire years (WY 2002-2007), both the region of the Moonlight Fire and Grizzly Ridge follow similar annual basin-averaged fSCA trends $(r=0.92)$. Before the fire the Moonlight Fire area had on average $17 \%$ less basin-averaged fSCA than Grizzly Ridge. After the fire, however, the Moonlight Fire area had an average of $26 \%$ more fSCA than Grizzly Ridge. The Moonlight Fire and Grizzly Ridge domains are also sensitive to winter precipitation, including the amount of precipitation and the duration of the snow season. The total precipitation as well as the length of the snow season in the area of the Moonlight Fire and Grizzly Ridge were above average in WY 2005 (Table 2) and yielded more fSCA, while WY 2007 was dry and resulted in less basin-averaged fSCA (Fig. 7). For the area of the Moonlight Fire, WY 2012 lies within the pre-fire interval and is similar to the pre-fire average, but may be climate-induced. Annual precipitation in WY 2012 is $380 \mathrm{~mm}$ (the Moonlight Fire area) and $520 \mathrm{~mm}$ (Grizzly Ridge), which corresponds to the lower fSCA. Annual basinaveraged fSCA estimates in Grizzly Ridge note only one (WY 2011) statically significant increase in fSCA during the post-fire period of WY 2008-2012, which is attributed to the 
larger-than-average annual precipitation and length of snow season $(1200 \mathrm{~mm})$.

After the fire there are significantly higher annual basinaveraged fSCA estimates based on slope aspect and soil burn severity (bold values denote statistical significance; Table 3). Regardless of slope aspect and burn severity, statistically significant increases in fSCA for the Moonlight Fire area are observed from WY 2008 to $2011(P<0.01)$. WY 2012 in all aspects and burn severity is not significantly different than pre-fire fSCA values but is still relatively high considering that it also received the lowest amount of total precipitation in the 11-year study period. Generally the high soil burn severity areas within the Moonlight Fire domain have slightly larger annual average fSCA values than moderate and low unburned (Table 3).

\subsection{Annual melt-out dates}

Annual melt-out dates are estimated for Grizzly Ridge and the area of the Moonlight Fire based on the $70 \%$ exceedance (10\% basin-averaged fSCA) threshold established from the canopy-adjusted MODSCAG fSCA cumulative distribution functions. At $10 \%$ coverage, the domain will have lost the vast majority of its snowpack due to melt. Annual melt-out dates for Grizzly Ridge and the Moonlight Fire region are compared for pre-fire and post-fire years (Fig. 8). Although the melt-out dates are variable from year to year based on annual snow conditions, Grizzly Ridge and the Moonlight Fire region melt-out dates are relatively similar pre-fire, during which it is observed that the area of the Moonlight Fire typically melts out an average of 1.5 days after Grizzly Ridge and ranges from -0.5 to 7 days with a standard deviation of 3 days (Fig. 8 b).

The average long-term pre-fire difference in melt-out dates (1.5 days) between the area of the Moonlight Fire and the control basin, Grizzly Ridge, is used to estimate the expected melt-out day for WY 2008-2012 assuming no fire (Fig. 8a; red solid diamonds). After the fire, the observed annual difference in melt-out dates between the area of the Moonlight Fire and Grizzly Ridge shows an average decrease of 7.5 days and more variability, with a standard deviation of 11 days (Fig. 8b). Thus relative to pre-fire averages, the Moonlight Fire area melts out an average of 9 days earlier. After the fire, the area melts out 1-23 days before Grizzly Ridge each year except for 2012, when melt-out occurs 5 days after Grizzly Ridge (Fig. 8).

\section{Discussion}

Daily remote sensing products MODSCAG and MOD10A1 were used to evaluate spatial and temporal changes in snow cover extent over the Moonlight Fire region and Grizzly Ridge from WY 2002 to 2012. MOD10A1 generates higher fSCA estimates than MODSCAG, which concurs with other studies that show the linear snow-mapping algorithm and the current NDVI threshold (Klein et al., 1998) do not differentiate between vegetation types and result in overestimates of fSCA (Rittger et al., 2013). Elevated pre-fire fSCA estimates dampen the fire signal which should increase viewable snow cover seen from MODIS. The MODSCAG product has a higher linear correlation to soil burn severity than MOD10A1 ( $r=0.56$ and $r=0.43$, respectively) and on average identifies larger increases in post-fire fSCA than MOD10A1 due to its ability to un-mix a combination of spectral signals within each pixel. Since the primary goal of this study is to evaluate the effects of wildfire on the spatial and temporal distribution of viewable snow cover, the results prompted the use of MODSCAG fSCA estimates for the remaining analysis.

Long-term basin-averaged MODSCAG fSCA estimates demonstrate statistically significant increased fSCA in the Moonlight Fire domain after the fire (WY 2008-2011; $P<$ $0.01)$ compared to pre-fire averages. Based on observations, years with high pre-fire fSCA estimates (i.e., WY 2005) are more representative of the snow season duration than the total winter precipitation. However, non-canopy-adjusted MODSCAG fSCA values in the Moonlight Fire had an average of $43 \%$ more fSCA than pre-fire years due to the stand-replacing fire and the removal of forest canopy, despite a decrease in annual precipitation of $100 \mathrm{~mm}$ and an average annual temperature of $1{ }^{\circ} \mathrm{C}$ from pre- to post-fire. Prefire, non-canopy-adjusted fSCA ensembles in both basins followed similar trends $(r=0.96)$, but there is a notable increase from non-canopy-adjusted MODSCAG fSCA in the Moonlight Fire region as compared to Grizzly Ridge of $26 \%$, post-fire.

A decomposition of fSCA in the Moonlight Fire area based on slope aspect and soil burn severity using the EPC is employed to investigate the influence of each attribute. Results show statistically significant increases in fSCA from WY 2008 to 2011 regardless of slope aspect and soil burn severity because of acute changes in vegetation structure and the resulting exposure of more snow cover. Water year 2012 is the only year after the fire that does not show statistically significant changes in fSCA compared to average pre-fire conditions and are attributed to the lowest recorded precipitation in the 11-year study period. Compared to the pre-fire low precipitation year (WY 2007), which received slightly more precipitation than WY 2012, and WY 2012 in Grizzly Ridge, fSCA is still increased by nearly $20 \%$ in the Moonlight Fire region.

In this study, it was beneficial to investigate MODSCAG fSCA estimates adjusted for canopy cover using Eq. (5) and non-adjusted estimates. Using the two estimates there is a recognizable change in $\mathrm{fSCA}$ due to the reduced vegetation fraction that is apparent as post-fire fSCA ensembles increase and begin to approach the canopy-adjusted values. This analysis identifies the importance in incorporating dynamic vegetation fractions when using the canopy adjustment. Static vegetation fractions are likely to result in large overestimates 

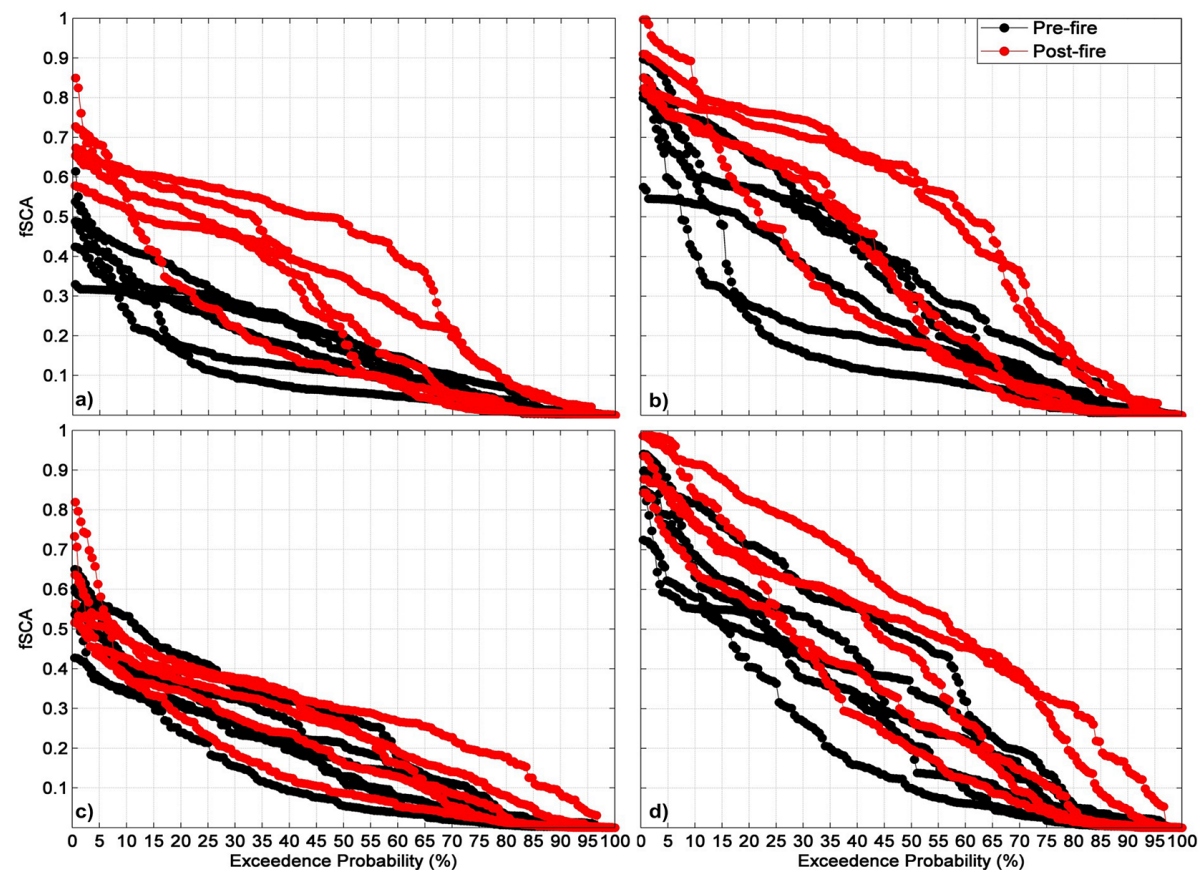

Figure 5. Annual cumulative frequency curves of daily basin-averaged non-canopy-adjusted MODSCAG fSCA for the Moonlight Fire area (a) and Grizzly Ridge (c) and canopy-adjusted MODSCAG fSCA for the Moonlight Fire area (b) and Grizzly Ridge (d). Black lines with black circles represent extreme pre-fire fSCA years (highest and lowest annual curves) and red circles represent post-fire annual curves.
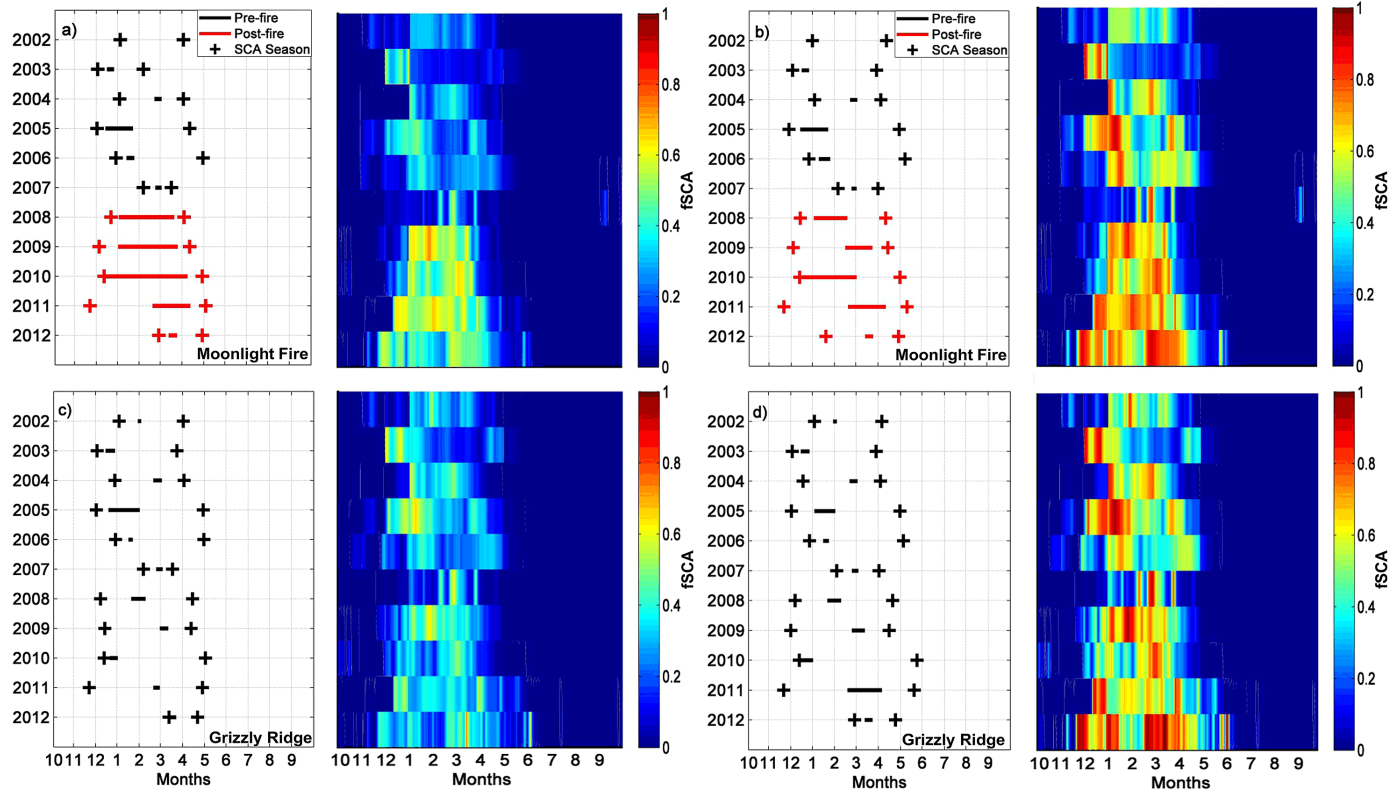

Figure 6. Temporal trends in snow cover of the consecutive number of high snow-cover days (pre-fire exceedance probability $\leq 10 \%$; represented by black and red lines) with respect to the length of snow season (exceedance probability $\geq 70 \%$; represented by black and red crosses) for Grizzly Ridge (c) and (d) and the Moonlight Fire area (a) and (b). Color maps show annual daily basin-averaged fSCA patterns. (b) and (d) are canopy-adjusted MODSCAG fSCA. 

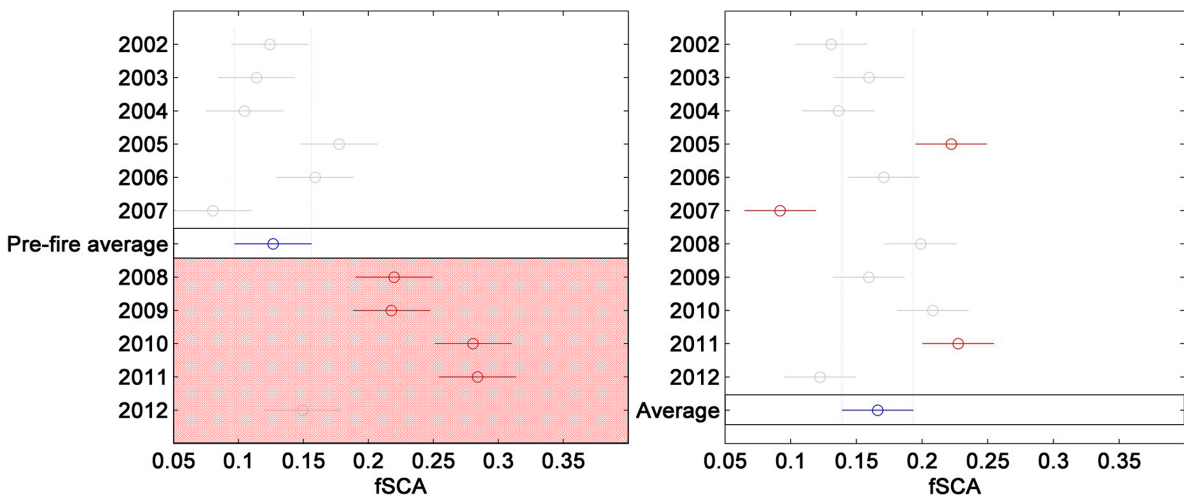

Figure 7. Basin-averaged ANOVA results for the Moonlight Fire area (left) and Grizzly Ridge (right) (99\% confidence interval). The post-fire years are shaded for the Moonlight Fire area.

Table 3. ANOVA results based on basin attributes for area of the Moonlight Fire. Bold font denotes statistical significance $(P<0.01)$, post-fire years are set italic.

\begin{tabular}{|c|c|c|c|c|}
\hline Slope aspect & South [fSCA] & North [fSCA] & West [fSCA] & East [fSCA] \\
\hline WY 2002 & 0.13 & 0.12 & 0.12 & 0.13 \\
\hline WY 2003 & 0.12 & 0.10 & 0.11 & 0.13 \\
\hline WY 2004 & 0.11 & 0.10 & 0.10 & 0.11 \\
\hline WY 2005 & 0.18 & 0.17 & 0.17 & 0.19 \\
\hline WY 2006 & 0.16 & 0.15 & 0.15 & 0.17 \\
\hline WY 2007 & 0.08 & 0.08 & 0.08 & 0.09 \\
\hline Pre-fire average & 0.13 & 0.12 & 0.12 & 0.14 \\
\hline WY 2008 & 0.22 & 0.22 & 0.21 & 0.23 \\
\hline WY 2009 & 0.23 & 0.22 & 0.21 & 0.23 \\
\hline WY 2010 & 0.29 & 0.28 & 0.27 & 0.29 \\
\hline WY 2011 & 0.29 & 0.29 & 0.27 & 0.32 \\
\hline WY 2012 & 0.15 & 0.16 & 0.14 & 0.16 \\
\hline Soil-burn severity & High [fSCA] & Moderate [fSCA] & \multicolumn{2}{|c|}{ Low-unburned [fSCA] } \\
\hline WY 2002 & 0.11 & 0.13 & \multicolumn{2}{|c|}{0.15} \\
\hline WY 2003 & 0.09 & 0.12 & \multicolumn{2}{|c|}{0.14} \\
\hline WY 2004 & 0.09 & 0.11 & \multicolumn{2}{|c|}{0.12} \\
\hline WY 2005 & 0.16 & 0.18 & \multicolumn{2}{|c|}{0.20} \\
\hline WY 2006 & 0.14 & 0.16 & \multicolumn{2}{|c|}{0.18} \\
\hline WY 2007 & 0.07 & 0.08 & \multicolumn{2}{|c|}{0.10} \\
\hline Pre-fire average & 0.11 & 0.13 & \multicolumn{2}{|c|}{0.15} \\
\hline WY 2008 & 0.23 & 0.22 & \multicolumn{2}{|c|}{0.21} \\
\hline WY 2009 & 0.24 & 0.22 & \multicolumn{2}{|c|}{0.21} \\
\hline WY 2010 & 0.30 & 0.28 & \multicolumn{2}{|c|}{0.27} \\
\hline WY 2011 & 0.30 & 0.29 & \multicolumn{2}{|c|}{0.27} \\
\hline WY 2012 & 0.15 & 0.15 & \multicolumn{2}{|c|}{0.15} \\
\hline
\end{tabular}

of fSCA after a fire as a result of unnecessary linear scaling of fSCA.

Cumulative distribution functions of canopy and noncanopy-adjusted basin-averaged MODSCAG fSCA are developed for the Moonlight Fire area and Grizzly Ridge to investigate post-fire shifts in snow cover and establish high snow cover and melt-out thresholds. Using the KS test, we note that annual post-fire fSCA distribution (WY 20082011 ) is elevated up to $40 \%$ compared to the long-term prefire distribution, and are significantly different at $\alpha=0.01$. This represents a higher probability of high fSCA values across the Moonlight Fire area. Before the fire, the $10 \%$ 

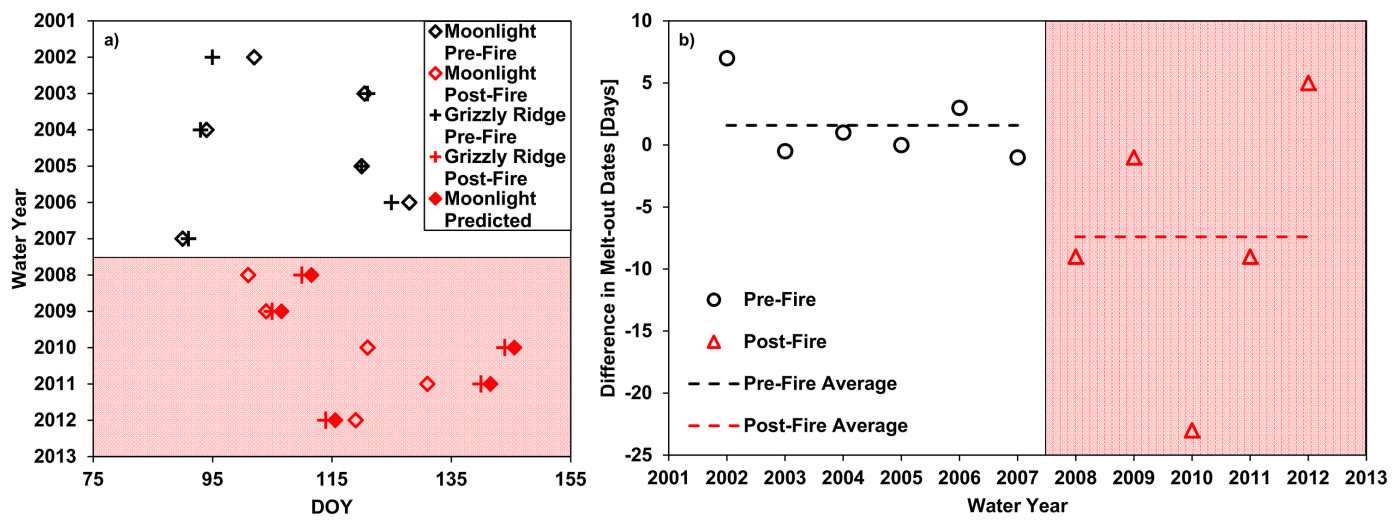

Figure 8. Basin-averaged snow cover melt-out dates for the area of the Moonlight Fire and Grizzly Ridge (a). Relative difference in melt-out dates (Moonlight Fire area-Grizzly Ridge) from the area of the Moonlight Fire and Grizzly Ridge (b).

exceedance threshold (defined as high snow cover) corresponded to an average snow coverage of $33 \%$ across the domain using non-canopy-adjusted fSCA estimates and $60 \%$ coverage using the adjusted fSCA values. Using these values as thresholds, it was determined that after the fire there is an average $81 \%$ increase in the number of high snow coverage days (i.e., days exhibiting higher than $33 \%$ snow coverage or higher than $60 \%$ snow coverage using the non-canopyadjusted and canopy-adjusted fSCA estimates, respectively) compared to pre-fire conditions and the control basin. Significant changes in the number of days with high snow coverage from elevated annual fSCA cumulative distribution functions compared to both pre-fire conditions and the control basin are a consequence of the fire and the removal of forest vegetation. It is likely that the increase in fSCA is directly related to additional exposure of the snow surface that was once hidden by forest canopy.

Significant changes in fSCA over the Moonlight Fire domain influence basin melt-out dates. Based on the $70 \%$ exceedance probability threshold established from the cumulative distribution functions, the differences in melt-out dates between the Moonlight Fire area and Grizzly Ridge are similar before the fire, only differing on average by 1.5 days. After the fire (WY 2008-2011) the entire Moonlight Fire domain melts out, on average, 9 days earlier compared to prefire conditions, with some years melting out up to 23 days early. The significant increases in exposed snow area from reductions in forest canopy cover increase the amount of solar radiation that reaches the snowpack. Early melt due to changes in the snowpack energy balance is consistent with smaller-scale field-based studies by Gleason et al. (2013) and Harpold et al. (2013). Changes in melt-out dates can have significant implications for water resource managers in the western US who rely on mountain snowpack for a majority of their water supply (Bales et al., 2006). The shifts observed in this study have important implications for reservoir operation, downstream water rights, and overall ecosystem health and recovery. Changes in snowmelt timing can heavily in- fluence the partitioning of snowmelt water (Molotch et al., 2009) and ultimately downstream water availability. Early snowmelt may also result in summer soil moisture deficits (Westerling et al. 2006), further exacerbating the effects of climate change. Snow is a natural storage reservoir for water and understanding the timing of the water's release into the system is critical for downstream resource managers. Following a large disturbance such as a wildfire, the altered system can no longer be managed under typical assumptions (Milly et al., 2008). To further complicate post-fire snow dynamics, snowpack melt-out dates are also correlated to forest types and species present in the Sierra Nevada (Barbour et al., 2002) and may influence plant phenology and vegetation types during the recovery or regeneration period.

According to this study, there is little evidence of canopy recovery from WY 2008 to 2012 over the Moonlight Fire area to pre-fire conditions as compared to the control basin, Grizzly Ridge. Basin-averaged fSCA and melt-out dates for WY 2012 fall within pre-fire averages, but this apparent return or recovery to pre-fire values is partly influenced by climate; WY 2012 had a low annual basin-averaged fSCA because of lower than normal precipitation totals. The sustained post-fire increase in remotely sensed fSCA in the area of the Moonlight Fire and earlier melt-out dates is a function of canopy loss. Similar to previous post-fire ecosystem studies, recovery is not expected until there is full canopy regeneration or until the system reaches a new equilibrium (Meixner and Wohlgemuth, 2003; Kinoshita and Hogue, 2011).

\section{Conclusions}

Continuous mapping of mountainous snow at $500 \mathrm{~m}$ resolution using remote sensing techniques has seldom been applied to answer forest disturbance-related hydrologic questions. Long-term analysis identified distinct differences in the pre- and post-fire snow cover and total visible snow over the burned domain (the area of the Moonlight Fire) when 
compared to a control basin (Grizzly Ridge). The changes in snow coverage and melt-out dates from WY 2002 to 2012 in the area of the Moonlight Fire are attributed to the removal of vegetation after the fire and are driven by corresponding changes in the snowpack energy balance. Specific key findings of this study include the following:

- MODSCAG's spectral mixing algorithm identifies snow cover in forested areas and is better correlated to soil burn severity compared to MOD10A1. MODSCAG is suited to identify changes in snow cover due to reductions in canopy cover after a wildfire.

- There is significantly more basin-averaged fSCA $(P<$ $0.01)$ after the fire due to a reduction of canopy cover and therefore an increased viewable snow area.

- There are significant increases in the total number of high snow-cover days after fire, based on pre- and postfire cumulative distribution functions.

- Using the relative difference in melt-out dates between the area of the Moonlight Fire and Grizzly Ridge, the Moonlight Fire domain melts out, on average, 9 days earlier after the fire.

- There is minimal spatial or temporal recovery of canopy and snow cover 5 years after the fire.

Climate change and increasing wildfire frequency and size have the potential to highly alter mountain snowpacks. The release of advanced snow mapping products provides a tool for the improved application of remote sensing data to better understand hazards such as fire and offers a unique opportunity for future long-term monitoring and research. The successful application of MODSCAG to the Moonlight Fire burn area provides the first watershed-scale analyses of snow cover and snowmelt detection after a large forest fire.

The shifts in the spatial and temporal distribution of snow throughout the year have significant implications for snow accumulation and melt patterns. This study advocates the application of remote sensing products such as MODSCAG for its rigorous spectral mixing analysis, which can contribute additional insight of regional post-fire snowpack and recovery studies. Remote sensing application improves our understanding and prediction of snowmelt behavior and is crucial for water resources and management, especially in regions that are highly dependent on snowpack and subject to frequent and acute forest disturbances.

Acknowledgements. Special thanks to Thomas Painter and his colleagues on the snow hydrology team at NASA JPL for the management and distribution of the MODSCAG product. Support for this research was provided by an NSF RAPID Grant (no. EAR1361454) as well as an NSF Hydrologic Sciences Program CAREER Grant (no. EAR0846662).

Edited by: S. Uhlenbrook

\section{References}

Bales, R. C., Molotch, N. P., Painter, T. H., Dettinger, M. D., Rice, R. and Dozier, J.: Mountain hydrology of the western United States, Water Resour. Res., 42, W08432, doi:10.1029/2005WR004387, 2006.

Barbour, M., Kelley, E., Maloney, P., Rizzo, D., Royce, E., and Fites-Kaufmann, J.: Present and past old-growth forests of the Lake Tahoe Basin, Sierra Nevada, US, J. Veg. Sci., 13, 461-472, doi:10.1111/j.1654-1103.2002.tb02073.x, 2002.

Brown, A. E., Zhang, L., McMahon, T. A., Western, A. W., and Vertessy, R. A.: A review of paired catchment studies for determining changes in water yield resulting from alterations in vegetation, J. Hydrol., 310, 28-61, doi:10.1016/j.jhydrol.2004.12.010, 2005.

Burke, M. P., Hogue, T. S., Kinoshita, A. M., Barco, J., Wessel, C., and Stein, E. D.: Pre- and post-fire pollutant loads in an urban fringe watershed in Southern California, Environ. Monit. Assess., 185, 10131-10145, doi:10.1007/s10661-0133318-9, 2013.

Burles, K. and Boon, S.: Snowmelt energy balance in a burned forest plot, Crowsnest Pass, Alberta, Canada, Hydrol. Process., 25, 3012-3029, doi:10.1002/hyp.8067, 2011.

California Department of Forestry and Fire Protection: Fire Perimeters, Geospatial Data Presentation Form: vector digital data available at: http://frap.cdf.ca.gov/data/frapgisdata-subset.php, last access: December 2012.

Cowpertwait, P., Ocio, D., Collazos, G., de Cos, O., and Stocker, C.: Regionalised spatiotemporal rainfall and temperature models for flood studies in the Basque Country, Spain, Hydrol. Earth Syst. Sc., 17, 479-494, doi:10.5194/hess-17-479-2013, 2013.

Daly, C., Neilson, R. P., and Phillips, D. L.: A statistical topographic model for mapping climatological precipitation over mountainous terrain, J. Appl. Meteorol., 33, 140-158, doi:10.1175/15200450(1994)033<0140:astmfm>2.0.co;2, 1994.

Daly, C., Taylor, G., Gibson, W., and Ams: The PRISM approach to mapping precipitation and temperature, 10th Conference on Applied Climatology, 10-12, 1997.

Daly, C., Gibson, W. P., Taylor, G. H., Johnson, G. L., and Pasteris, P.: A knowledge-based approach to the statistical mapping of climate, Clim. Res., 22, 99-113, doi:10.3354/cr022099, 2002.

DiMiceli, C. M., Carroll, M. L., Sohlberg, R. A., Huang, C. M., Hansen, C., and Townshend, J. R. G.: Annual Global Automated MODIS Vegetation Continuous Fields (MOD44B) at $250 \mathrm{~m}$ Spatial Resolution for Data Years Beginning Day 65, 2000-2010, Collection 5 Percent Tree Cover. University of Maryland, College Park, 2011.

Dozier, J.: Spectral signature of alpine snow cover from the Landsat Thermatic Mapper, Remote Sens. Environ., 28, 9-22, doi:10.1016/0034-4257(89)90101-6, 1989.

Dozier, J., Painter, T. H., Rittger, K., and Frew, J. E.: Timespace continuity of daily maps of fractional snow cover and albedo from MODIS, Adv. Water Resour., 31, 1515-1526, doi:10.1016/j.advwatres.2008.08.011, 2008.

Ebel, B. A., Hinckley, E. S., and Martin, D. A.: Soil-water dynamics and unsaturated storage during snowmelt following wildfire, Hydrol. Earth Syst. Sc., 16, 1401-1417, doi:10.5194/hess-16-14012012, 2012. 
Faria, D. A., Pomeroy, J. W., and Essery, R. L. H.: Effect of covariance between ablation and snow water equivalent on depletion of snow-covered area in a forest, Hydrol. Process., 14, 26832695, doi:10.1002/1099-1085(20001030)14:15<2683::AIDHYP86>3.0.CO;2-N, 2000.

Fry, J., Xian, G., Jin, S., Dewitz, J., Homer, C., Yang, L., Barnes, C., Herold, N., and Wickham, J.: Completion of the $2006 \mathrm{Na}-$ tional Land Cover Database for the Conterminous United States, Photogramm. Eng. Remote Sens., 77, 858-864, 2011.

Gleason, K. E., Nolin, A. W., and Roth, T. R.: Charred forests increase snowmelt: Effects of burned woody debris and incoming solar radiation on snow ablation, Geophys. Res. Lett., 40, 46544661, doi:10.1002/grl.50896, 2013.

Hall, D. K., Salomonson, V. V., and Riggs. G. A.: MODIS/Terra Snow Cover Daily L3 Global $500 \mathrm{~m}$ Grid, Version 5, Boulder, Colorado USA, NASA DAAC at the National Snow and Ice Data Center, 2006.

Hansen, M. C., DeFries, R. S., Townshend, J. R. G., Carroll, M., Dimiceli, C., and Sohlberg, R. A.: Global Percent Tree Cover at a Spatial Resolution of 500 Meters: First Results of the MODIS Vegetation Continuous Fields Algorithm. Earth Interact., 7, 1-15, doi:10.1175/10873562(2003)007<0001:GPTCAA>2.0.CO;2, 2003.

Harpold, A. A., Biederman, J. A., Condon, K., Merino, M., Korgaonkar, Y., Nan, T., Sloat, L. L., Ross, M., and Brooks, P. D.: Changes in snow accumulation and ablation following the Las Conchas Forest Fire, New Mexico, USA, Ecohydrology, 7, 440 452, doi:10.1002/eco.1363, 2013.

Kattelmann, R. C., Berg, N. H., and Rector, J.: The potential for increasing streamflow from Sierra-Nevada watersheds, Water Resour. Bull., 19, 395-402, 1983.

Kinoshita, A. M. and Hogue, T. S.: Spatial and temporal controls on post-fire hydrologic recovery in Southern California watersheds, Catena, 87, 240-252, doi:10.1016/j.catena.2011.06.005, 2011.

Klein, A. G., Hall, D. K., and Riggs, G. A.: Improving snow cover mapping in forests through the use of a canopy reflectance model, Hydrol. Process., 12, 1723-1744, doi:10.1002/(SICI)10991085(199808/09)12:10/11<1723::AID-HYP691>3.0.CO;2-2, 1998.

Lane, P. N. J., Sheridan, G. J., and Noske, P. J.: Changes in sediment loads and discharge from small mountain-catchments following wild-fire in south eastern Australia, J. Hydrol., 331, 495-510, doi:10.1016/j.jhydrol.2006.05.035, 2006.

Massey Jr, F. J.: The Kolmogorov-Smirnov test for goodness of fit, J. Am. Stat. Assoc., 46, 68-78, 1951.

Maurer, E. P., Rhoads, J. D., Dubayah, R. O., and Lettenmaier, D. P.: Evaluation of the snow-covered area data product from MODIS, Hydrol. Process., 17, 59-71, doi:10.1002/hyp.1193, 2003.

Meixner, T. and Wohlgemuth, P. M.: Climate variability, fire, vegetation recovery, and watershed hydrology. In Proceedings of the First Interagency Conference on Research in the Watersheds, Benson, Arizona, October 2003, 651-656, 2003.

Milly, P. C. D., Betancourt, J., Falkenmark, M., Hirsch, R. M., Kundzewicz, Z. W., Lettenmaier, D. P., and Stouffer, R. J.: Climate change - Stationarity is dead: Whither water management?, Science, 319, 573-574, doi:10.1126/science.1151915, 2008.

Molotch, N. P., Brooks, P. D., Burns, S. P., Litvak, M., Monson, R. K., McConnell, J. R., and Musselman, K.: Ecohydrological controls on snowmelt partitioning in mixed-conifer sub-alpine forests. Ecohydrology, 2, 129-142, doi:10.1002/eco.48, 2009.

Molotch, N. P. and Margulis, S. A.: Estimating the distribution of snow water equivalent using remotely sensed snow cover data and a spatially distributed snowmelt model: A multi-resolution, multi-sensor comparison, Adv. Water Resour., 31, 1503-1514, doi:10.1016/j.advwatres.2008.07.017, 2008.

Morton, D. C., DeFries, R. S., Shimabukuro, Y. E., Anderson, L. O., Espírito-Santo, F. D. B., Hansen, M., and Carroll, M.: Rapid Assessment of Annual Deforestation in the Brazilian Amazon Using MODIS Data. Earth Interact., 9, 1-22, doi:10.1175/EI139.1, 2005.

Painter, T. H., Barrett, A. P., Landry, C. C., Neff, J. C., Cassidy, M. P., Lawrence, C. R., McBride, K. E., and Farmer, G. L.: Impact of disturbed desert soils on duration of mountain snow cover, Geophys. Res. Lett., 34, L12502, doi:10.1029/2007GL030284, 2007.

Painter, T. H., Rittger, K., McKenzie, C., Slaughter, P., Davis, R. E., and Dozier, J.: Retrieval of subpixel snow covered area, grain size, and albedo from MODIS, Remote Sens. Environ., 113, 868879, doi:10.1016/j.rse.2009.01.001, 2009.

$\mathrm{Pu}, \mathrm{Z} ., \mathrm{Xu}, \mathrm{L}$. , and Salomonson, V. V.: MODIS/Terra observed seasonal variations of snow cover over the Tibetan Plateau, Geophys. Res. Lett., 34, L06706, doi:10.1029/2007GL029262, 2007.

Raleigh, M. S., Rittger, K., Moore, C. E., Henn, B., Lutz, J. A., and Lundquist, J. D.: Ground-based testing of MODIS fractional snow cover in subalpine meadows and forests of the Sierra Nevada, Remote Sens. Environ., 128, 44-57, doi:10.1016/j.rse.2012.09.016, 2013.

Rittger, K., Painter, T. H., and Dozier, J.: Assessment of methods for mapping snow cover from MODIS, Adv. Water Resour., 51, 367-380, doi:10.1016/j.advwatres.2012.03.002, 2013.

Salomonson, V. V. and Appel, I.: Estimating fractional snow cover from MODIS using the normalized difference snow index, Remote Sens. Environ., 89, 351-360, doi:10.1016/j.rse.2003.10.016, 2004.

Smakhtin, V. U.: Low flow hydrology: a review, J. Hydrol., 240, 147-186, doi:10.1016/s0022-1694(00)00340-1, 2001.

Stednick, J. D.: Monitoring the effects of timber harvest on annual water yield, J. Hydrol., 176, 79-95, doi:10.1016/00221694(95)02780-7, 1996.

Stein, E. D., Brown, J. S., Hogue, T. S., Burke, M. P., and Kinoshita, A.: Stormwater contaminant loading following southern California wildfires, Environ. Toxicol. Chem., 31, 2625-2638, doi:10.1002/etc.1994, 2012.

Stephens, S. L., Collins, B. M., and Roller, G.: Fuel treatment longevity in a Sierra Nevada mixed conifer forest, Forest Ecol and Manag., 285, 204-212, doi:10.1016/j.foreco.2012.08.030, 2012.

Swanson, F. J.: Fire and Geomorphic Processes, in: Proceedings, Fire regimes and ecosystems conference, Honolulu, HI, 11-15 December 1979, Gen. Tech. Rep., WO-23, USDA, Washington, DC, 401-420, 1981.

Tucker, C. J.: Red and photographic infrared linear combinations for monitoring vegetation, Remote Sens. Environ., 8, 127-150, 1979.

USDA Forest Service Remote Sensing Applications Center (RSAC): Moonlight Fire occuring on the Plumas National Forest - 2007. U.S. Geol. Surv., Sioux Falls, South Dakota, USA, 
available at: http://edc.usgs.gov (last access: 20 December 2012), 2007.

Varhola, A., Coops, N. C., Weiler, M., and Moore, R. D.: Forest canopy effects on snow accumulation and ablation: An integrative review of empirical results, J. Hydrol., 392, 219-233, doi:10.1016/j.jhydrol.2010.08.009, 2010.

Webb, A. A., Kathuria, A., and Turner, L.: Longer-term changes in streamflow following logging and mixed species eucalypt forest regeneration: The Karuah experiment, J. Hydrol., 464, 412-422, doi:10.1016/j.jhydrol.2012.07.034, 2012.
Westerling, A. L., Hidalgo, H. G., Cayan, D. R., and Swetnam, T. W.: Warming and earlier spring increase western US forest wildfire activity- Science, 313, 940-943. doi:10.1126/science.1128834, 2006.

Wildland Fire Incidents: US Historic Fire Perimeters. Geospatial Data Presentation Form: vector digital data, available at:www. geomac.gov, last access: 1 October 2013. 